\title{
Support for Families During COVID-19 in Spain: The iCygnus Online Tool for Parents
}

\author{
Lucia Halty ${ }^{1,2}$ (1) $\cdot$ Amaia Halty ${ }^{1,2} \cdot$ Virginia Cagigal de Gregorio ${ }^{1,2}$ \\ Accepted: 6 April 2021 / Published online: 17 April 2021 \\ (c) The Author(s), under exclusive licence to Springer Science+Business Media, LLC, part of Springer Nature 2021
}

\begin{abstract}
On March 14, 2020 one of the strictest confinements in Europe was imposed on the citizens of Spain. The online tool for parents, iCygnus, was designed to reduce the psychological impact generated by the pandemic on the child population (2-12 years of age) through automatic recommendations to parents based on individual responses about their parenting styles and their child's characteristics. The profiles of the 710 families indicate a higher prevalence of internalizing and externalizing behavior problems in children, as well as a relationship between punitive parenting in families where the parents lost their jobs due to the coronavirus disease (COVID-19). The usefulness of the help offered by iCygnus was evaluated after 6 weeks, and almost $80 \%$ of the families indicated that they used the recommendations and that they helped them in their relationship with their children.
\end{abstract}

Keywords ICygnus $\cdot$ Conduct problems $\cdot$ Support for families

\section{Introduction}

The first cases of individuals affected by the new coronavirus, COVID-19 (coronavirus disease 2019), were described in Wuhan (Chinese province of Hubei) at the end of December 2019. Then, by March 11, 2020, the World Health Organization [1] had already declared the spread of this virus a pandemic. The disease spread across all continents at an unprecedented rate.

The State of Alarm was decreed in Spain on March 14, 2020 and, with this, one of the strictest confinements in Europe was imposed on the entire country. Unlike the citizens of other countries, such as Germany or France, Spanish citizens were required to stay home at all times, and only activities aimed at acquiring basic necessities or attending health or work centers were authorized. Children stopped

Lucia Halty

lhalty@ comillas.edu

Amaia Halty

ahalty@ comillas.edu

Virginia Cagigal de Gregorio

vcagigal@comillas.edu

1 UNINPSI Universidad Pontificia Comillas, Madrid, Spain

2 Universidad De Comillas, 3-5, 28049 Madrid, Spain attending school and performing all their routines and lost social contact with friends and family. Spanish society as a whole, like that of many other countries, was facing a situation of isolation for the first time and experts predict that it will have repercussions on mental health, such as anxiety and depression disorders, substance abuse, and domestic violence or child abuse, among others [2]. A review of previous confinement experiences in other countries also indicates that likely psychological consequences include post-traumatic stress symptoms, confusion, and anger [3].

Recommendations from organizations such as the United Nations Committee on Children's Rights [4] urged governments with very restrictive isolation measures, such as the case of Spain, to authorize children under 14 years of age to go out on the street several hours a day, due to concern regarding the effects that the restrictive lockdown may have on this group. In this statement, the Committee states that many children may be physically, psychologically, and emotionally affected by the confinement imposed.

Research on the emotional impact of natural disasters on children indicates that they are more vulnerable than adults to trauma that disrupts their daily lives [5]. There are very few studies that evaluate the psychological impact that this confinement situation is having on children, but some experts suggest effects at different levels such as concentration difficulties, boredom, irritability, lack of rest, 
nervousness, feelings of loneliness, restlessness, and worries [6]. Some recent research underlines how the increase of parental stress or parental burnout due to the pandemic situation makes parents more likely to engage in child abuse and neglect $[7,8]$. To these data are added those obtained by Xie et al., who determined that $22.6 \%$ of school-age students had depressive symptoms and $18.9 \%$ had symptoms of anxiety, in a sample of children in China, during the confinement in the months of February to March, 2020 [9]. Likewise, Brooks et al. point out the possible presence of posttraumatic stress based on previous studies [3], such as that of Sprang \& Silman, in which children in a confined state presented post-traumatic stress levels four times higher than those of unconfined children [10]. Also, the loss of routines can make them lose their sense of structure, predictability, and security.

Several authors point out the negative impact of prolonged suspension of academic activities on children [8, 11]. Lee highlighted the change in routine that it entails for children, the loss of social contact, the uncertainty for those children during critical school years, such as changes in the educational cycle or loss of all secondary benefits that the school provides for children, as well as individual therapies for children with special educational needs [12]. In Spain, children will go without school for six months since the last stages of return to normal after confinement overlap with the start of the summer holidays. Poletti \& Raballo consider that the prolonged closure of schools is an important stressor for children, which increases the risk of loneliness, addiction to video games and compulsive consumption of screens, alteration of circadian rhythms, as well as, in some cases, being victims of or witnessing domestic violence [13]. All this is added to the academic gaps that the closure of schools imply for some children, which in turn increases the inequalities of the most vulnerable.

For the time being, studies that evaluate the psychological impact of the pandemic also speak of very negative consequences for the adult population. One of the first articles on the effects of confinement in China reported that more than half of respondents reported moderate or severe psychological impact and one third reported moderate or severe anxiety symptoms [14]. Tian et al., also investigated levels of psychopathology among the Chinese citizenship and found that more than $70 \%$ of participants presented moderate to high levels of psychopathology, especially in terms of phobic anxiety, obsessive compulsion, psychoticism, and interpersonal sensitivity [15]. Although some couples and families have improved their relationships quality during lockdown [16] studies warn about the risk of tension in couple relationships as a consequence of the pandemic acting as a stressor [17].

Despite the limited existing data, it seems evident that the combination of the psychological impact on children and on the adult population makes families one of the major sources of vulnerability to this crisis. Parents, in addition to bearing the stress derived from the direct impact of the disease on the social environment, adjustment to new working conditions or temporary or permanent loss of employment, and the physical and psychological consequences of confinement, have had to face and sustain the whole impact of this situation on their children. COVID-19 is a stressor and anxiety factor for many parents [18]. Parental stress, in turn, is a risk factor for children's well-being $[19,20]$

Families thus face a host of stressors that can negatively influence parenting. Humphreys et al. [21] explain that this confinement situation, where children's routines are altered, is prone to generate in them an increase in challenging behaviors that tend to provoke harsh responses from parents more easily. These authors also consider that, if the stress of the parents' own individual experience is added to this, it is easier for them to manifest outbursts of temper or even exercise physical or verbal abuse [22]. Without a doubt, these relational dynamics impact the emotional state of children, who are permeable to the changes that occur in their environment, translating the unpredictability or stress of the environment into symptoms of anxiety, greater behavioral problems, or sadness [23].

These reactions in children, although they are understood as an adaptive response to the exceptional situation they are experiencing, require immediate responses and resources focused on reducing their discomfort. Therefore, shortly after the global pandemic was decreed, several national and international organizations began to offer aid resources for families. Several authors consider it necessary to act quickly in the face of this crisis situation, offering citizens and professionals resources to contain the possible negative effects $[2,22]$. Orrù et al. suggest that mental health professionals should create easily disseminated tools or questionnaires capable of detecting the presence of psychopathological indicators and, if possible, that could be accompanied by recommendations according to their needs [23].

These guidelines and recommendations, although useful for framing the new situation that families are facing, lack specific recommendations that can help both diverse families (such as those that use authoritarian, uninvolved, permissive, or authoritative parenting styles), or those who have children in their family nucleus with a great need for physical activity, very shy children, children with a great need to relate to their peers, or children with aggressive behavioral manifestations. Faced with situations where stress factors accumulate, it is important to know minimally which characteristics of children are most difficult for each family to handle and which coping strategies they use to foster family well-being.

In order to help families overcome this crisis with the least possible psychological impact, it was necessary to 
create several online support tools. Thus, the iCygnus tool emerged.

\section{The iCygnus Tool}

iCygnus is an online tool created to provide psychological support to families with children between 2 and 12 years of age, during the COVID-19 pandemic. One of the most important goals for this research team is to promote the prevention of children's behavior problems. Although adolescence is a developmental period of special importance, we have focused the psychological orientations of the iCygnus tool between the ages of 2 and 12 in order to help parents in their difficult task and prevent the appearance of major behavioral problems as a consequence of home confinement. This tool was designed according to 4 fundamental criteria. First, that it should offer psychological guidance tailored as much as possible to the characteristics of the child and the educational style of the parents or guardians. Second, that it should be kept short. Given the emotional overload involved in a confinement situation, it was necessary to develop a tool that could shape the child and the educational style of the parents or guardians with as few questions as possible. Third, psychological counseling had to be automatic and offered in real time. In many cases, the results of scientific advances are returned to society with a certain delay. However, in this case, families needed answers on how to handle their children at home at a very specific and immediate moment. Finally, it was necessary for the tool to reach many people - the distribution and diffusion had to be massive.

Achieving these 4 goals was only possible if technology was used. To do this, a questionnaire was designed on the Google Forms platform with 4 sections. An initial sociodemographic section included questions to assess the situation in which the family found itself and subjects were given all the necessary information about the treatment of their data.

A second section aimed at evaluating the characteristics of the child to assess, on the one hand, their abilities and difficulties through the instrument Strengths and Difficulties Questionnaire (SDQ) [24] and, on the other, to assess their sociability through the EAS sociability subscale (Emotionality Activity Sociability Temperament Survey for Children) [25]. The SDQ instrument was selected because with few questions it evaluates the variables of emotional symptoms, conduct problems, hyperactivity, peer problems, and prosocial behavior, which have been shown to especially impact the child population affected by the COVID-19 pandemic $[19,22]$. The orientations offered by the tool were different depending on whether the children scored more or less on each of these variables. For example, if the child's profile had high scores for emotional symptoms, iCygnus offered parents strategies to help their child reduce their discomfort. As with high scores in behavior problems, parents were offered guidance on understanding and managing these behaviors in a stressful situation, such as prolonged confinement. Similarly, if the child's profile yielded high scores for prosocial behavior, the iCygnus tool highlighted the child's strengths for parents by promoting positive interactions. The child's sociability levels were also evaluated through the EAS subscale since the situation of social isolation could cause profiles with high scores on this variable to experience confinement in a more negative way. In these cases, the iCygnus guidelines were aimed at channeling the need for social contact through online platforms or video calls.

The third section evaluated the parenting patterns used by parents or guardians through the Alabama Parenting Questionnaire Spanish version (APQ) [26]. Considering the greater time that parents were going to spend with their children due to confinement, it was deemed essential to draft the messages of the psychological guidelines taking into account how they relate to their children. Thus, the iCygnus tool reinforced the profiles of parents who obtained high scores in authoritative parenting, as well as offering alternative parenting strategies to parents who scored higher on authoritarian, uninvolved, and permissive parenting.

The guidelines offered by the tool, based on data from the parents' responses, are built on evidence-based practices, such as the principles of attachment intervention programs [27-29], and the principles of family and couple therapy [30-32].

The evolutionary stage of the sample of children was also taken into account to generate the guidelines, adjusting the message for parents depending on whether their child was in the pre-school stage (2-5 years) or in the middle childhood stage (6-12 years). It is essential that parents have specific clues that have been proven effective, given certain characteristics of their children and their own parental style. In summary, the iCygnus guidelines try to promote psychological flexibility, self-care, and self-compassion as basic elements to face parenting in crisis situations [34], as well as to focus on the description of the family strengths and return a comprehensive view of parental attitudes. Furthermore, the guidelines are based on promoting family routines, values, and norms, as well as increasing positive reinforcement [33]. Likewise, the tool offers systemic guidelines, aimed at promoting healthy couple relationship dynamics, which will minimize potential parental conflict as a consequence of the changes and interactions caused by confinement.

In the last section, the iCygnus tool asked the person completing the form to provide an email to which the guidelines would immediately be sent based on their answers. In this case, the parents or guardians were the informants of the child's behaviors, as well as the parenting guidelines. In the tool's feedback, it was made clear at all times that the guidelines received did not constitute a psychological evaluation or substitute a therapeutic process if needed. 
With these considerations, the iCygnus tool was created to help Spanish families, with children between 2 and 12 years old, to overcome the crisis caused by the COVID19 pandemic. As a consequence of the tool's great acceptance among the population, the objectives of this article are, firstly, to describe the profile of the families that have made use of the iCygnus tool and, secondly, to evaluate the usefulness of this tool through user satisfaction.

\section{Method}

\section{Participants}

The sample of individuals who used the iCygnus tool was collected from March 29 to May 4, 2020, and there was a total of 710 families who, during their confinement in Spain, requested advice to overcome the crisis. The link to access the iCygnus tool was distributed by newsgroups and university websites, as well as by the Community of Madrid College of Physicians and the official website of the Government of the Community of Madrid.

The reference individuals who report on a child's and family's situation are made up of $84.5 \%$ mothers, $13.66 \%$ fathers, and $1.83 \%$ legal guardians, with a mean age of 41.25 years $(S D=5.64)$. The percentage of boys in the sample is $54.37 \%$, and girls $45.63 \%$. The mean age of the children in the sample is 6.4 years $(S D=3.15)$, with $45.92 \%$ being children between 2 and 5 years old; and $54.08 \%$ children between 6 and 13 years old.

Regarding the size of the home in which the confinement occurs, Table 1 shows that the highest percentage live in houses that are more than 120 square meters. With regard to the number of people living at the same address, the highest percentage is 4 people. Finally, most of the families in this sample were able to keep their jobs by telecommuting.

Institutional Review Board approval was obtained. To be included in the sample, participants had to document that they were of adult age (i.e., 18 years of age or older), and agreed to sign a written online informed consent in which the study was extensively described.

\section{Measures}

As it has been previously highlighted, the iCygnus tool consists of several instruments that are described below:

\section{The Strengths and Difficulties Questionnaire (SDQ)}

The SDQ is a behavioral screening questionnaire that assesses psychiatric symptomatology among young people [20]. The scale queries 25 positive and negative attributes and produces a total difficulties score, and 5 subscale scores-emotional symptoms, conduct problems ("often loses temper"), hyperactivity, peer problems, and prosocial behavior ("shares readily with other children, for example toys, treats, pencils"). The SDQ is scored using a 3-point Likert scale where 0 equals 'not true'; 1 equals 'somewhat true'; and 2 equals 'certainly true'; several questions are reverse-scored. In order to carry out the orientations based on age groups, the SDQ version of Goodman for children between 6-12 years of age and the 2013 Spanish version of Ezpeleta et al. for preschoolers were used [34]. In this research, reliability data (alpha) for preschoolers ( $2-5$ years) are emotional symptoms $=0.64$, conduct problems $=0.67$, hyperactivity $=0.75$, peer problems $=0.52$, prosocial behavior $=0.58$ and total $=0.75$. Reliability data (alpha) for intermediate childhood (6-12 years) are emotional symptoms $=0.67$, conduct problems $=0.66$, hyperactivity $=0.77$, peer problems $=0.68$, prosocial behavior $=0.70$ and total $=0.81$.

To select the groups with high and low scores in each variable of the SDQ, we used the cut-off points proposed by authors Ezpeleta et al. [34] for validation of the instrument among the Spanish population. These authors also show cut-off points to classify scores as normal ( $0-3$ emotional symptoms; $0-2$ conduct problems; $0-5$ hyperactivity; $0-2$ peer problems; and $6-10$ prosocial behavior), borderline ( 4 emotional symptoms; 3 conduct problems; 6 hyperactivity; 3 peer problems; and 5 prosocial behavior), and abnormal (5-10 emotional symptoms; $4-10$ conduct problems; 7-10 hyperactivity; $4-10$ peer problems; and $0-4$ prosocial behavior.)

Table 1 Descriptive statistics of the sample obtained with iCygnus

\begin{tabular}{|c|c|c|c|c|c|}
\hline Size of home & Percentage & Same address & Percentage & Work situation & Percentage \\
\hline 50 square meters & 1.69 & 2 people & 5.07 & Face-to-face work & 12.68 \\
\hline $50-80$ square meters & 27.18 & 3 people & 28.87 & Telework & 59.01 \\
\hline $80-120$ square meters & 26.06 & 4 people & 46.06 & TERF & 13.10 \\
\hline \multirow[t]{2}{*}{ Greater than 120 square meters } & 45.07 & 5 people & 13.94 & Lost job & 2.96 \\
\hline & & 6 or more & 6.06 & Did not work before & 12.25 \\
\hline
\end{tabular}

TERF temporary employment regulation file and stopped working 


\section{Emotionality Activity Sociability Temperament Survey for Children (EAS)}

To assess children's preference to be in the company of others, the EAS sociability subscale (Emotionality Activity Sociability Temperament Survey for Children) [25, 35] was used. The subscale consists of 5 items (alpha in our study $=0.81$ ) and the items were rated between 1 (my child's behavior is never like this) and 5 (my child's behavior is always like this). To select the groups with high and low scores in this subscale, we used the + 1SD criterion from Spanish adaptations of EAS [37].

\section{Alabama Parenting Questionnaire (APQ)}

To evaluate parenting style we used the Spanish validation of the APQ by de la Osa et al., [26]. This scale is formed by 24 items rated on a 5-point Likert-type scale ranging from 1 (never) to 5 (always). It is made up of 3 subscales that evaluate positive parenting ("you have a friendly talk with your child"), inconsistent parenting ("you threaten to punish your child and then do not actually punish him/her") and punitive parenting ("you spank your child with your hand when he/ she has done something wrong"). Reliability data (alpha) in this study were $0.93,0.71$ and 0.63 , respectively.

To select the groups with high and low scores in each variable of the APQ, we used the cut-off points proposed by authors de la Osa et al. [26] for validation of the instrument among the Spanish population. The cutoff points for positive parenting are 12-26; 27-45; and 46-60. The cutoff points for inconsistent parenting are $7-15 ; 16-26$; and $27-35$. The cutoff points for punitive parenting are 5-11; 12-19; and 20-25.

\section{iCygnus Algorithm}

When an individual submitted the form to the Google Forms platform, a previously trained algorithm decided what orientation to offer according to the established profile. In this way, a script was run from Google Forms in which all possible orientations were stored (18 in total). For each of the 9 subscales of the SDQ (emotional symptoms, conduct problems, hyperactivity, peer problems, and prosocial behavior), sociability, and APQ (positive parenting, inconsistent parenting, and punitive parenting) that make up iCygnus, the cut-off points provided by their respective authors to divide responses into high-score and low-score were used. The cutoff points, both for the children and parents variables make it possible to dichotomize each subscale, which forms 18 different categories. In this way, specific guidelines were developed according to whether the child presented (1) or not (0) emotional problems, behavior problems, hyperactivity, or problems with peers, prosocial behavior, and sociability; and according to whether the parents presented (1) or not (0) positive parenting, inconsistent parenting, or punitive parenting. Thus, parents or guardians immediately received guidance tailored to their profile.

\section{Feedback from the iCygnus Tool}

At the end of the questionnaire, participants were asked if they would like the team of psychologists to stay in contact to them. They were not informed of any specific aim of this second contact. Six weeks after data collection, the families who agreed to keep in contact with the researchers answered the following questions to assess the usefulness and help of the tool: "I have applied the tool's guidelines with my son", "The tool's guidelines have helped me to manage the situation of confinement with my son", "I would recommend this tool to a friend or acquaintance", "If this procedure of receiving personalized guidance becomes an App that you can consult whenever you want, would you use it?". The response format was 0 (not at all) to 5 (very much).

\section{Statistical Analyses}

Descriptive analyses, student's $t$ tests for independent samples, and one-way ANOVA were performed to create the profiles of the families who requested help through iCygnus. Statistical analyses were performed with the IBM SPSS Statistics 26.0 statistical package [27].

\section{Results}

Table 2 shows the descriptive data pertaining to the profile of children aged 2-5 years and for children 6-12 years, in each of the subscales and total SDQ. When comparing the 2 age groups, as reported by the parents or guardians, no significant differences were found in the total SDQ score $(T=0.15$, $p=0.88$ ). When we analyzed the SDQ subscales, children between 6 and 12 years of age presented significantly

Table 2 Means and standard deviations of the total SDQ and subscales

\begin{tabular}{|c|c|c|c|c|c|}
\hline & \multicolumn{2}{|c|}{$\begin{array}{l}2-5 \text { years } \\
(N=326)\end{array}$} & \multicolumn{2}{|c|}{$\begin{array}{l}6-12 \text { years } \\
(N=384)\end{array}$} & \multirow[t]{2}{*}{ Variable range } \\
\hline & $M$ & $S D$ & $M$ & $S D$ & \\
\hline Total SDQ & 12.94 & 5.29 & 12.87 & 6.30 & $0-40$ \\
\hline Emotional symptoms & 2.31 & 1.92 & 3.19 & 2.31 & $0-10$ \\
\hline Conduct problems & 3.04 & 2.08 & 2.46 & 1.99 & $0-10$ \\
\hline Hyperactivity & 5.61 & 2.51 & 5.18 & 2.65 & $0-10$ \\
\hline Peer problems & 1.99 & 1.67 & 2.04 & 2.01 & $0-10$ \\
\hline Prosocial behavior & 7.30 & 1.87 & 7.43 & 2.07 & $0-10$ \\
\hline
\end{tabular}

$M$ mean, $S D$ Standard Deviation 
more emotional problems than children between 2 and 5 $(T=5.46, p=0.0001)$. On the other hand, children aged 2 to 5 years, presented significantly more behavioral problems $(T=3.76, p=0.0001)$ and more hyperactivity levels ( $T=2.18, p=0.030$ ), than children aged 6 to 12 years.

As observed in Fig. 1, the description of the normal, borderline, and abnormal groups of the SDQ instrument shows that $23.62 \%$ of children between 2 and 5 years of age, and $25.52 \%$ of children between 6 and 12 years of age, have abnormally high scores on the total SDQ difficulty scale. Of the rest of the sub-scales, behavior problems and hyperactivity had the highest percentages of problems in the confinement situation in both age groups.

No statistically significant differences were found between the 2 age groups in the sociability variable evaluated with the EAS subscale $\left(T=1.26, p=0.21, M_{2-5 \text { years }}=17.60\right.$, $\left.S D=13.62, M_{6-12 \text { years }}=17.24, S D=13.91\right)$. Table 3 shows the descriptive data of the APQ subscales and only finds statistically significant differences in the positive parenting subscale $(T=2.34, p=0.019)$. Parents of 2 to 5 -year-old children reported using more positive parenting strategies.

Table 4 shows the descriptive data of the boys and girls taking into account their age group. The results indicate that in the 2 to 5 year-old-stage, boys present higher levels of hyperactivity $(T=3.12, p=0.002)$ and lower levels of prosocial behavior $(T=2.57, p=0.011)$ than girls. In the 6 to 12-year-old-stage, boys obtained higher scores in behavior problems $(T=1.99, p=0.046)$ and hyperactivity $(T=3.59, p=0.0001)$; and lower scores in prosocial behavior $(T=3.74, p=0.0002)$ than girls. It can also be observed that parents apply more positive parenting with girls than with boys in this age range. ( $T=2.19, p=0.029)$.

As seen in Table 5, families with children between 6 and 12 years old who have lost their jobs as a consequence of the COVID-19 crisis use a more punitive parenting method with their children $\left(F_{(4,379)}=2.79, p=0.026\right)$ than families who have continued to work remotely and, the children of parents who lost their jobs during the pandemic have higher levels in the total SDQ than children whose parents were able to telework during the crisis. $\left(F_{(4,379)}=3.09, p=0.016\right)$.

Families were asked if they wanted the researchers to contact them again later, and $47.88 \%$ of the sample answered "yes". Table 6 shows that families who do want to maintain contact have children with higher scores in prosocial behavior ( 2 and 5 years) $(T=2.09, p=0.037)$, and that they have higher positive parenting scores $(T=2.22, p=0.027)$ than those who did not want to maintain contact.

Six weeks after starting data collection, these families were asked to assess the usefulness and help of the iCygnus tool. Responses were received from $26 \%$ of the families asked and, as seen in Fig. 2, 83.12\% of the sample used the recommendations (score of 3 or more points), it helped $88.74 \%$ manage the situation with their child during confinement (score of 3 or more points), 92.14\% would recommend this tool to an acquaintance or friend (score of 3 points or more), and $91.01 \%$ of the sample would use an App with this recommendations format.

\section{Discussion}

The main objective of this research was to develop an online tool (iCygnus) to provide psychological support to Spanish families with children between 2 and 12 years old during the COVID-19 pandemic. The data from this study describes the profiles of families that have used the online tool during confinement, between the months of March and May 2020, as well as the evaluation of the users on iCygnus.

In this study, the data shows that children, during the confinement decreed in Spain, presented a much higher level than usual in the total difficulties scale, as well as in all its subscales, according to normative data in the Spanish population [36, 37]. The high prevalence found may be due to the effects of confinement and are in the same line as other studies that warn of the possible negative consequences of confinement in children [13, 39]. Although this higher prevalence is likely to represent an adaptive response of children to the situation they are living in depending on personal characteristics and context resilience factors [40, 41], it is advisable to monitor the effect of confinement on children in the long term, since the early onset of internalizing and externalizing problems, together with the experience of traumatic episodes, considerably increase the risk of serious behavior problems and mood disorders in adolescence and adulthood [38-42]. For this reason, the guidelines sent from the iCygnus tool placed special emphasis on offering parents strategies to help their children promote their emotional regulation, since this variable is a protective factor for the development of behavioral problems in the future [43].

According to age, the results show more emotional problems in the group of older children (6 to 12 years old) than in that of younger children ( 2 to 5 years old), while there are more externalizing behavior problems and hyperactivity in the latter group. These results are consistent with those found by Bongers et al., who report an increase in internalizing problems as children get older while externalizing problems decrease [44].

On the other hand, given that one of the most significant changes in children's lives, caused by home confinement, was the loss of social contact with their peers, it was decided to include a specific sociability measure. In this way, children's parents who had high sociability scores could receive specific guidance on how to make a digital transformation of their children's relationships with their friends. The data obtained from this study indicate that there are no statistically significant differences between the comparison groups 


\section{EMOTIONAL SYMPTOMS}

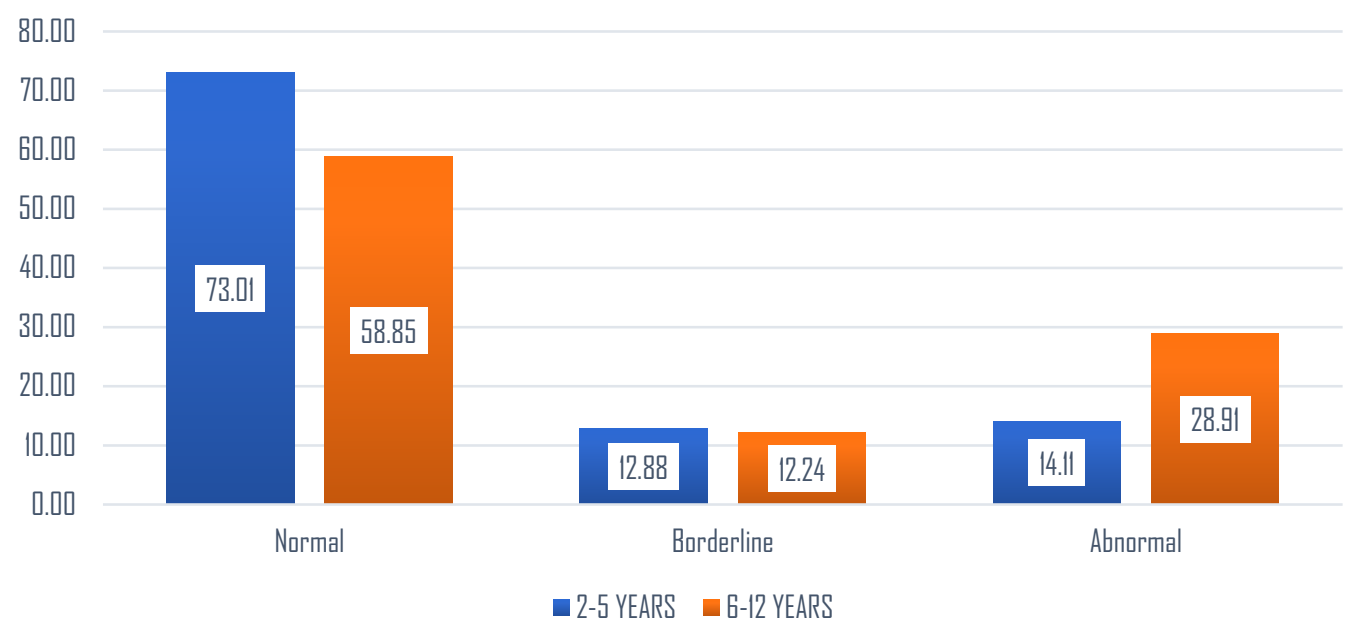

\section{CONDUCT PROBLEMS}

60.00
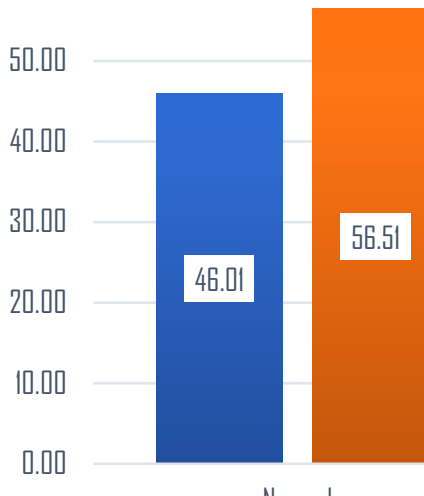

Normal

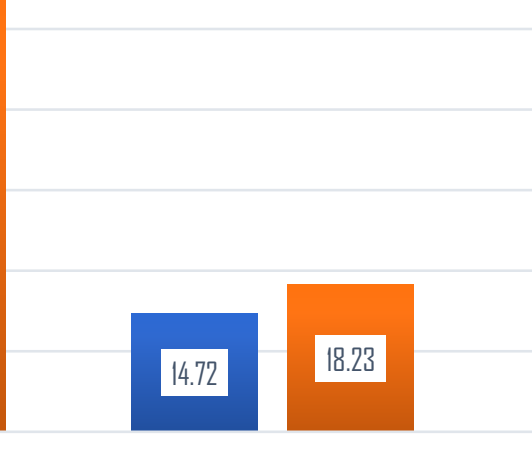

Borderline

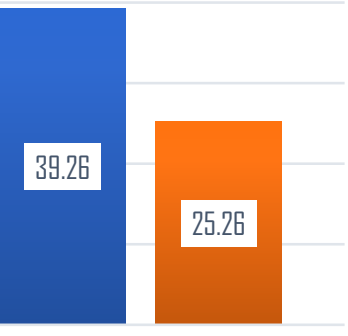

Abnormal

-2-5 YEARS G-I2 YEARS

\section{HYPERACTIVITY}

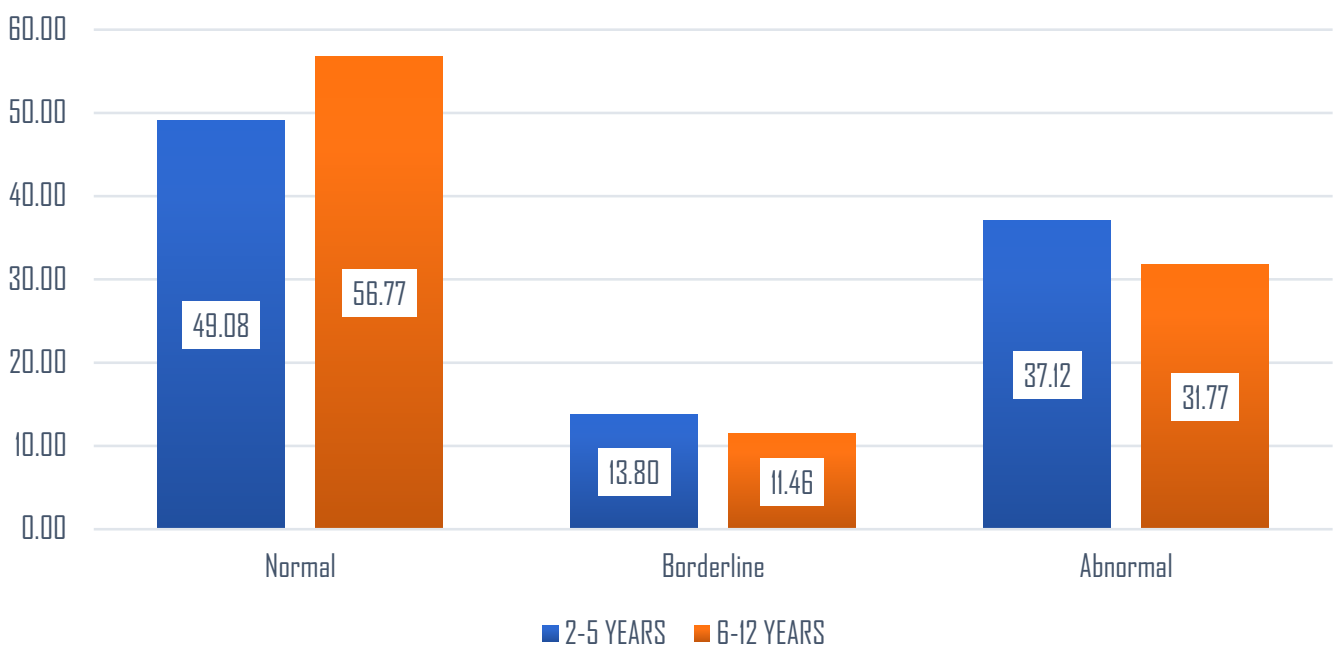

Fig. 1 Percentages of each of the subscales and total SDQ in the normal, borderline, and abnormal groups 


\section{PEER PROBLEMS}

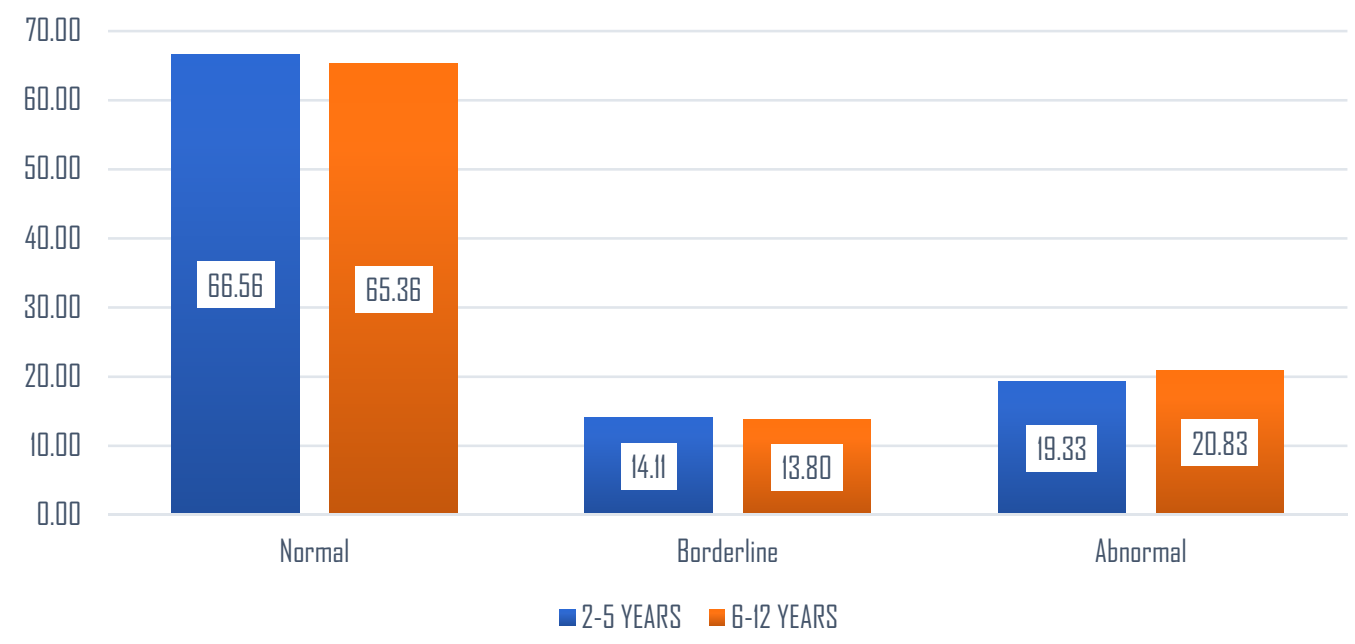

\section{PRDSOCIAL BEHAVIDUR}

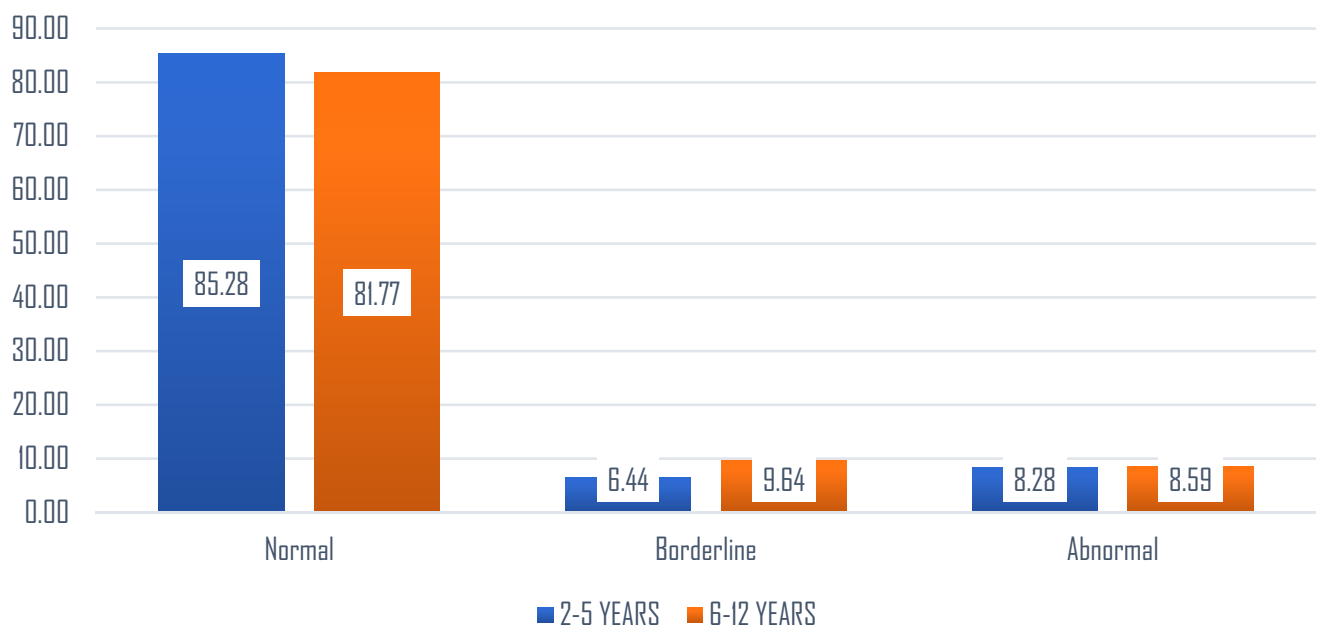

\section{TDTAL}

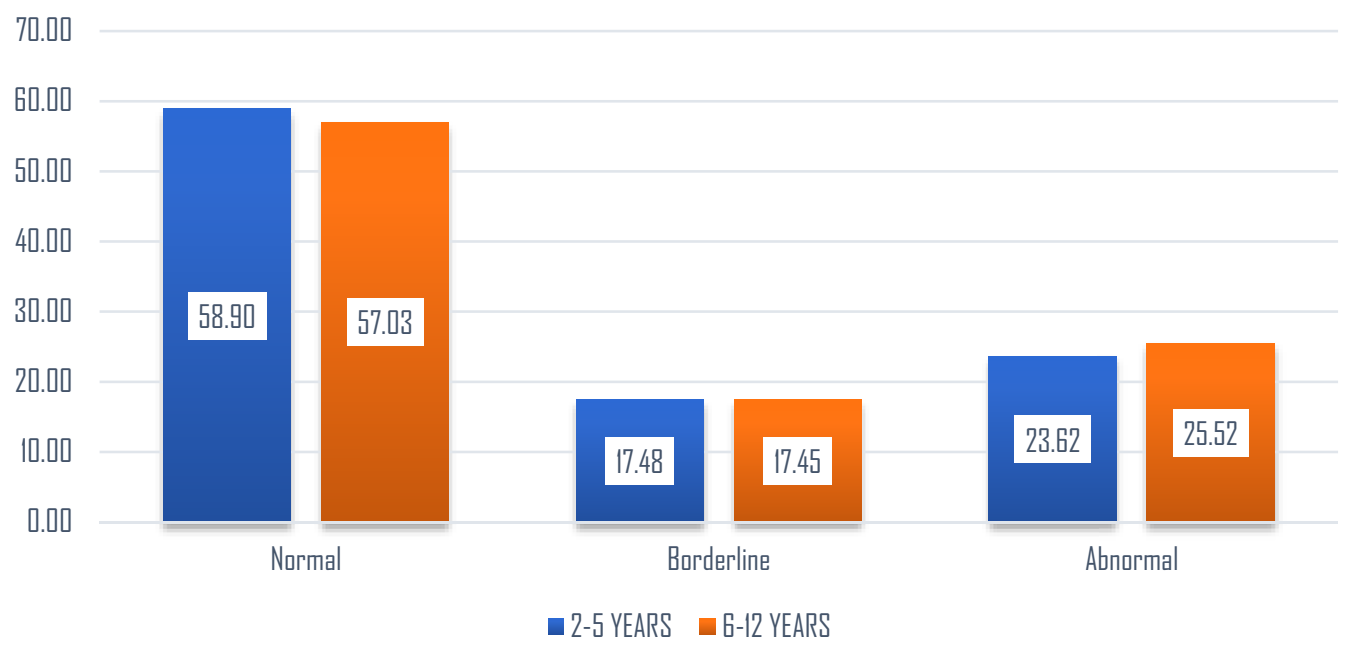

Fig. 1 (continued) 
Table 3 Averages and standard deviations of the APQ subscales

\begin{tabular}{|c|c|c|c|c|c|}
\hline & \multicolumn{2}{|c|}{$\begin{array}{l}2-5 \text { years } \\
(N=326)\end{array}$} & \multicolumn{2}{|c|}{$\begin{array}{l}6-12 \text { years } \\
(N=384)\end{array}$} & \multirow[t]{2}{*}{ Variable range } \\
\hline & $M$ & $S D$ & $M$ & $S D$ & \\
\hline Positive parenting & 50.04 & 8.31 & 48.59 & 8.20 & $12-60$ \\
\hline Inconsistent parenting & 14.36 & 4.06 & 14.89 & 4.60 & $7-35$ \\
\hline Punitive parenting & 8.07 & 2.37 & 8.24 & 2.50 & $5-25$ \\
\hline
\end{tabular}

$M$ mean; SD Standard Deviation

Table 4 Descriptive statistics by gender and age group in the SDQ, Sociability (EAS), and APQ
Table 5 Descriptive statistics according to employment situation during COVID-19 in families with children between 6 and 12 years of age
Table 6 Descriptive statistics of the subsequent contact variable with the SDQ, Sociability, (EAS) and the APQ of boys and girls in the different age groups. These results are similar to those found in other investigations [45], and although they may seem surprising in the context of the pandemic, our data indicate that the mean sociability in all comparison groups is approximately 17 points, with a maximum score of 20 points. That is, parents who consult the iCygnus tool report having highly sociable children, so they have received specific guidance to help their children channel their personal relationships in the new context of the pandemic.

\begin{tabular}{|c|c|c|c|c|c|c|c|c|}
\hline & \multicolumn{2}{|c|}{ Boys $2-5$ years old } & \multicolumn{2}{|c|}{ Girls $2-5$ years old } & \multicolumn{2}{|c|}{$\begin{array}{l}\text { Boys } 6-12 \text { years } \\
\text { old }\end{array}$} & \multicolumn{2}{|c|}{$\begin{array}{l}\text { Girls 6-12 years } \\
\text { old }\end{array}$} \\
\hline & $M$ & $S D$ & $M$ & $S D$ & $M$ & $S D$ & $M$ & $S D$ \\
\hline Total SDQ & 13.47 & 5.28 & 12.37 & 5.26 & 13.63 & 6.37 & 11.88 & 6.08 \\
\hline Emotional symptoms & 2.17 & 1.95 & 2.46 & 1.88 & 3.34 & 2.33 & 2.99 & 2.28 \\
\hline Conduct problems & 3.14 & 2.12 & 2.92 & 2.04 & 2.64 & 2.01 & 2.23 & 1.95 \\
\hline Hyperactivity & 6.02 & 5.34 & 5.16 & 7.02 & 5.60 & 2.62 & 4.63 & 2.60 \\
\hline Peer problems & 2.14 & 1.71 & 1.83 & 1.62 & 2.05 & 2.00 & 2.03 & 2.02 \\
\hline Prosocial behavior & 7.04 & 3.50 & 7.57 & 3.31 & 7.09 & 2.14 & 7.88 & 1.90 \\
\hline Sociability -EAS & 17.36 & 3.66 & 17.84 & 3.72 & 17.14 & 3.67 & 17.37 & 3.82 \\
\hline Positive parenting & 49.79 & 8.71 & 50.31 & 7.87 & 47.79 & 8.30 & 49.63 & 7.96 \\
\hline Inconsistent parenting & 14.35 & 4.04 & 14.37 & 4.09 & 15.04 & 4.54 & 14.70 & 4.68 \\
\hline Punitive parenting & 8.11 & 2.50 & 8.04 & 2.24 & 8.28 & 2.48 & 8.20 & 2.54 \\
\hline
\end{tabular}

$M$ mean; $S D$ Standard Deviation

\begin{tabular}{|c|c|c|c|c|c|c|c|c|c|c|}
\hline & \multicolumn{2}{|c|}{ On-site work } & \multicolumn{2}{|c|}{ Remote work } & \multicolumn{2}{|c|}{ Temporary file } & \multicolumn{2}{|c|}{ Loss of a job } & \multicolumn{2}{|c|}{$\begin{array}{l}\text { Did not work } \\
\text { before the } \\
\text { crisis }\end{array}$} \\
\hline & M & S.D & M & S.D & M & S.D & M & $S . D$ & M & S.D \\
\hline Total SDQ & 12.79 & 5.86 & 12.58 & 6.11 & 13.26 & 6.32 & 18.91 & 8.71 & 12.45 & 6.62 \\
\hline Punitive parenting & 7.96 & 2.13 & 8.08 & 2.42 & 8.72 & 2.94 & 10.45 & 3.85 & 8.26 & 1.99 \\
\hline
\end{tabular}

$M=$ mean $; S D=$ Standard Deviation

\begin{tabular}{|c|c|c|c|c|c|c|c|c|}
\hline & \multicolumn{2}{|c|}{$\begin{array}{l}\text { Yes }(2-5 \text { years } \\
\text { old) }\end{array}$} & \multicolumn{2}{|c|}{ No (2-5 years old) } & \multicolumn{2}{|c|}{$\begin{array}{l}\text { Yes (6-12 years } \\
\text { old) }\end{array}$} & \multicolumn{2}{|c|}{$\begin{array}{l}\text { No (6-12 years } \\
\text { old) }\end{array}$} \\
\hline & $M$ & $S D$ & $M$ & $S D$ & $M$ & $S D$ & $M$ & $S D$ \\
\hline Total SDQ & 12.76 & 4.68 & 13.11 & 5.83 & 13.14 & 6.36 & 12.64 & 6.25 \\
\hline Emotional symptoms & 2.23 & 1.79 & 2.38 & 2.04 & 3.23 & 2.29 & 3.15 & 2.33 \\
\hline Conduct problems & 2.98 & 1.95 & 3.09 & 2.20 & 2.65 & 2.02 & 2.29 & 1.95 \\
\hline Hyperactivity & 5.53 & 2.42 & 5.68 & 2.61 & 5.39 & 2.66 & 5.00 & 2.64 \\
\hline Peer problems & 2.02 & 1.67 & 1.95 & 1.68 & 1.87 & 1.98 & 2.19 & 2.02 \\
\hline Prosocial behavior & 7.52 & 1.77 & 7.08 & 1.93 & 7.35 & 2.04 & 7.50 & 2.11 \\
\hline Sociability -EAS & 17.27 & 3.68 & 17.92 & 3.69 & 17.31 & 3.78 & 17.18 & 3.70 \\
\hline Positive parenting & 50.55 & 8.16 & 49.55 & 8.44 & 49.58 & 7.56 & 47.72 & 8.64 \\
\hline Inconsistent parenting & 14.73 & 4.31 & 14.01 & 3.78 & 14.97 & 4.57 & 14.83 & 4.64 \\
\hline Punitive parenting & 8.32 & 2.23 & 7.84 & 2.49 & 8.16 & 2.38 & 8.32 & 2.61 \\
\hline
\end{tabular}

$M=$ mean $; S D=$ Standard Deviation 


\section{Recomendations implementations}

$50.00 \%$

$40.00 \%$

$30.00 \%$

$20.00 \%$

$10.00 \%$

$0.00 \%$

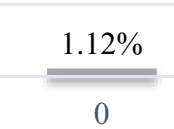

$5.62 \%$

1
$39.33 \%$

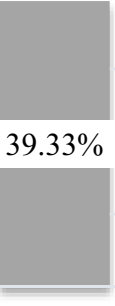

3

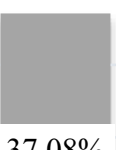

$37.08 \%$

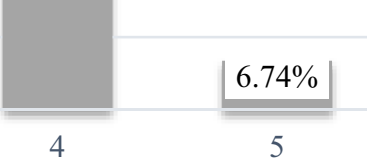

Recomendations helpfulness

$45.00 \%$

$40.00 \%$

$35.00 \%$

$30.00 \%$

$25.00 \%$

$20.00 \%$

$15.00 \%$

$10.00 \%$

$5.00 \%$

$0.00 \%$

$0.00 \%$

0

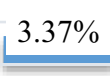

1

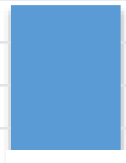

$39.33 \%$

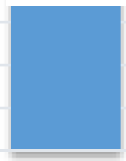

3

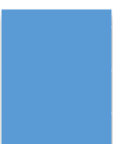

$37.08 \%$

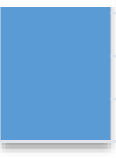

4

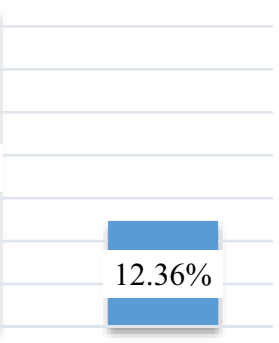

\section{Recommendation likelihood}

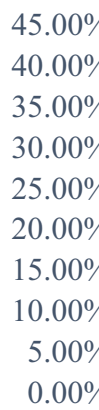

$45.00 \%$
$40.00 \%$
$35.00 \%$
$30.00 \%$
$25.00 \%$
$20.00 \%$
$15.00 \%$
$10.00 \%$
$5.00 \%$
$0.00 \%$

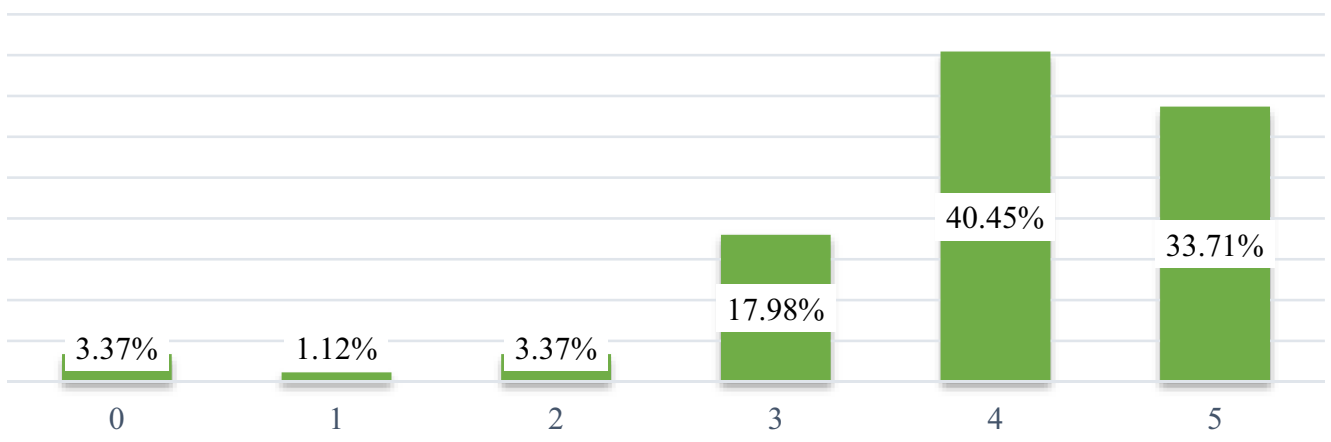

\section{App}

$8.99 \%$

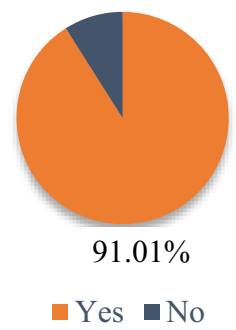

Fig. 2 Results of the assessment of the iCygnus tool 
Regarding the differences in children's age and gender, it was determined that, in the group of boys vs. girls up to 5 years old, there is a greater presence of hyperactivity and a lower level of prosocial behavior than in the girls. Furthermore, in the 6 to 12-year-old stage, a significant difference also exists regarding behavior problems in boys compared to girls. The differences between boys and girls in internalizing and externalizing variables varies throughout their development. Our data supports previous research indicating that, around the age of 4 years, boys tend to show more externalizing symptoms than girls. On the other hand, girls tend to internalize more near adolescence [40, 46, 47].

It is interesting to note that, although higher levels of behavior problems have appeared through the iCygnus tool, which are explainable due to the confinement situation, the results are consistent with the previous literature regarding distribution by gender and age, which confirms the instrument as a valid tool to evaluate behavior problems in children through an online platform for parents as informants, even in such a stressful situation as Covid-19 pandemic.

Regarding parenting styles, the data have shown a positive parenting in parents of children from 2 to 5 years of age, both for girls and for boys; in the 6 to 12 -year-old group, parents present more positive parenting towards girls than towards boys. Thus, parents in this study tend to show a more positive parenting style when their children are younger, and to a greater extent towards girls than towards boys, if they are older than 6 years. These findings support those of McHale et al. on parents' warmer treatment of younger children as well as girls [48, 49] and, at the same time, results point out that boys older than 6 years may have a higher tendency toward psychological well-being during lockdown than girls due to differential parental treatment.

Newton et al. determined that both maternal sensitivity and maternal mental state language can be used to directly predict children's prosociality [50]. In this difficult situation for children, it is crucial to promote parenting behaviors in parents that involve warm, contingent, and supportive responses to children's cues. Through mother-child conversation, a mother draws the child's attention to people's mental states and emotional experiences and can help both reduce the child's levels of discomfort and enhance their prosocial behavior.

The data from our study that speaks of a lower presence of externalizing problems in girls, together with a higher positive parenting, support the results of Woodward et al. who find that girls receive significantly more positive parenting than boys [51]. Differences in the etiology of positive parenting may be explained by developmental gender differences in child cognitive abilities and affection, such that girls may have more rewarding interactions with parents, evoking more positive parenting.
Different investigations have highlighted that parental stress and problems related to parental mental health are related to more problematic parental practices by parents [52]. The data from this study reveal this, noting that when parents of children between 6 and 12 years of age lost their jobs during the COVID-19 crisis, they present higher levels of punitive parenting than parents who were able to continue with their professional work through telework. In turn, the children of parents who lost their jobs present higher levels of emotional and behavioral problems. Although we cannot interpret these data as a causal relationship, a relationship is observed between a measure of indirect stress (job loss) and more punitive practices.

The crisis generated worldwide by the COVID-19 pandemic may explain these results, given that parents in confinement situations present $28 \%$ of symptoms that may justify a diagnosis of post-traumatic stress, which is a much higher figure than the $6 \%$ prevalence among non-confined parents [3]. On the other hand, if coexistence or circumstances are more difficult during quarantine, according to Orgilés et al., parents tend to report emotional problems in their children to a greater extent than when they are not living through situations of special difficulty [6]. It should also be kept in mind that a hostile parenting style increases the risk of joint development of internalizing and externalizing problems around the age of 5 [53].

In turn, children and adolescents closely observe their environment and the people around them, so that they perceive and react to the stress of their parents or caregivers and, at the same time, their well-being depends to a large extent on the well-being of their parents or caregivers [5]. Therefore, it can well be understood that parents subjected to the stress of coping with job loss show a parenting style with lower quality of relationship with their children. They, in turn, present higher levels of behavioral problems, in response to stress and the perceived lack of emotional availability of their parents.

The increased pressure experienced by many parents when combining the demands of work during confinement with childcare, which in turn are more susceptible to oppositional responses and disruptive behavior, along with stress linked to the economic situation, logistics, or due to concern for health, increases the risk of verbal and/or physical abuse by parents towards their children [17]. Loss of contact with other people and the distance from the school environment pose a greater risk for these children, since what they are experiencing within the home is not detectable [54]. In this sense, the data presented in this study show a correlation with punitive practices and higher parental stress levels; therefore, this is an aspect to pay special attention to.

The current crisis has generated an unprecedented demand for parental support and, therefore, it is essential to encourage parents to display their best educational skills and 
expand their repertoire of responses to promote the health and emotional well-being of their children $[11,34]$. The need for intervention proposals that accompany parents in this period of special difficulty is highlighted, to alleviate the tension associated with the exercise of parenting under these conditions and improve their relationship with children. This is the main reason for creating the iCygnus tool.

The second objective of this study was to analyze the perception of parents or guardians of children of the usefulness of the iCygnus tool, developed to intervene preventively and cushion the impact of confinement in the COVID-19 crisis.

People who accessed the tool were asked if they wanted the research team to contact them again. Out of the users who answered that they wanted to continue to maintain contact with the researchers versus those who did not, the parents of children 2 to 5 years old reported a higher level of prosocial behavior in their children and higher levels of positive parenting. These data indicate a concern in these parents for the well-being of their children by promoting positive parenting practices that help enhance prosocial behavior, both factors becoming protective elements for the development of subsequent psychological problems [50].

The assessment made by the families of the tool indicates that it has been very useful. Six weeks after the start of data collection, the vast majority of users who evaluated the usefulness of the tool indicated that they had used the iCygnus recommendations and that they had helped them manage confinement with their children.

Several authors maintain that, in the face of confinement, it is important for professionals in psychology and psychiatry to have access to citizens to offer help through online methodology with the aim of promoting their psychological and physical health and well-being [5, 55].

Poletti et al. indicate the need for political authorities to adequately balance the risks of child confinement against the risk of contagion and spread of the pandemic [13]. However, for situations in which this is the only possible measure, psychological support through digital platforms and online technology is essential, given that, if faced with the stressful or traumatic event, children receive adequate and responsive support from their parents or their main reference figures, most children return to levels of emotional and behavioral well-being prior to the traumatic experience [5].

Although this study offers promising results regarding the usefulness of the iCygnus tool, it is not without limitations. First of all, it should be noted that it is the parents or guardians themselves who report on the characteristics of their children (an issue that cannot be solved during confinement), and this fact may bias the data on children, further enhanced by the situation of stress or discomfort caused by COVID-19 in the parents themselves. Secondly, here are the profiles of a sample of families that sought this help during the first months of the COVID-19 pandemic. It would have been interesting to compare these profiles with those who did not seek out this help during confinement or in the course of their work. Thirdly, it is important to highlight that the data on satisfaction with the iCygnus tool were collected only from families who gave their consent for the research team to contact again. This can bias the interpretation of the data, so further research is required to confirm the usefulness of the iCygnus tool. Lastly, it is worth mentioning the low reliability data in the peer problems subscale for children between 2 and 5 years; therefore, the results in this variable should be interpreted with caution.

Two future lines of research emerge from this limitation. On the one hand, transforming the iCygnus link into an application that allows psychological triage to be carried out to refer families who are most at risk to specific resources. Almost $90 \%$ of the families that answered would use an application with these characteristics. Secondly, after 6 months, it would be advisable to reconnect with the families to see if the responses given at the start of the pandemic were due to an adaptive response or, on the contrary, the appearance of more severe family problems.

In conclusion, the present study provides valuable information in order to offer intervention and prevention strategies for future situations. It is important that researchers offer tools to the population to facilitate immediate help or guidance during crises. Research in general pays little attention to the implementation of effective interventions in real time, and the early detection of psychological distress is key in preventing problems from becoming chronic or sustained in the future [54]. This is what has been attempted with the design of this iCygnus tool.

\section{Summary}

The main objective of this research was to develop an online tool (iCygnus) to provide psychological support to Spanish families with children between 2 and 12 years old during the COVID-19 pandemic. The data from this study describes the profiles of families that have used the online tool during confinement, between the months of March and May 2020 in Spain, as well as the evaluation of the users on iCygnus. The current crisis has generated an unprecedented demand for parental support and, therefore, it is essential to encourage parents to display their best educational skills and expand their repertoire of responses to promote the health and emotional well-being of their children $[11,34]$. The need for intervention proposals that accompany parents in this period of special difficulty is highlighted, to alleviate the tension associated with the exercise of parenting under these conditions and improve their relationship with children. This is the main reason for creating the iCygnus tool. It is important that researchers 
offer tools to the population to facilitate immediate help or guidance during crises. Research in general pays little attention to the implementation of effective interventions [56] in real time, and the early detection of psychological distress is key in preventing problems from becoming chronic or sustained in the future.

Author Contribution LH Conceptualization, Methodology, Writing (original draft), and Supervision. AH Writing, review, and editing. VC Writing, review, and editing.

\section{References}

1. World Health Organization (2020). WHO Director-General's opening remarks at the media briefing on COVID-19 - 11 March 2020, as of 20 June 2020. https://www.who.int/dg/speeches/ detail/who-director-general-s-opening-remarks-at-the-media-brief ing-on-covid-19---11-march-2020

2. Galea S, Merchant RM, Lurie N (2020) The mental health consequences of COVID-19 and physical distancing: the need for prevention and early intervention. JAMA Int Med 180(6):817-818. https://doi.org/10.1001/jamainternmed.2020.1562

3. Brooks SK, Webster RK, Smith LE, Woodland L, Wessely S, Greenberg N, Rubin GJ (2020) The psychological impact of quarantine and how to reduce it: rapid review of the evidence. The Lancet 395:912-920. https://doi.org/10.1016/S0140-6736(20) 30460-8

4. Committee on the Rights of the Child (2020). The Committee on the Rights of the Child warns of the grave physical, emotional and psychological effect of the COVID-19 pandemic on children and calls on States to protect the rights of children, as of 20 June 2020. https://tbinternet.ohchr.org/_layouts/15/treatybodyexternal/Downl oad.aspx ?symbolno $=\mathrm{INT} \% 2 \mathrm{fCRC} \% 2 \mathrm{fSTA} \% 2 \mathrm{f} 9095 \& \mathrm{Lang}=\mathrm{en}$

5. Bartlett, J. D., Griffin, J. \& Thomson, D. (2020). Resources for Supporting Children's Emotional Well-being during the COVID19 Pandemic. Child Trends

6. Orgilés, M., Morales, A., Delvecchio, E., Mazzeschi, C., \& Espada, J. P. (2020). Immediate psychological effects of the COVID-19 quarantine in youth from Italy and Spain. https://doi. org/https://doi.org/10.31234/osf.io/5bpfz

7. Brown NUEVA, Doom SM, Lechuga-Peña JR, Watamura S, Koppels SE (2020) Stress and parenting during the global COVID-19 pandemic. Child Abuse Negl. https://doi.org/10.1016/j.chiabu. 2020.104699

8. Griffith NUEVA (2020) Parental burnout and child maltreatment during the COVID-19 pandemic. J Family Violence. https://doi. org/10.1007/s10896-020-00172-2]

9. Xie, X., Xue, Q., Zhou, Y., Zhu, K., Liu, Q., Zhang, J., \& Song, R. (2020). Mental Health Status Among Children in Home Confinement During the Coronavirus Disease 2019 Outbreak in Hubei Province, China. JAMA pediatrics, e201619. Advance online publication. https://doi.org/https://doi.org/10.1001/jamapediat rics.2020.1619

10. Sprang G, Silman M (2013) Posttraumatic stress disorder in parents and youth after health-related disasters. Disaster Med Public Health Prep 7(1):105-110. https://doi.org/10.1017/dmp.2013.22

11. Wang G, Zhang Y, Zhao J, Zhang J, Jiang F (2020) Mitigate the effects of home confinement on children during the COVID-19 outbreak. The Lancet 395:945-947. https://doi.org/10.1016/ S0140-6736(20)30547-X
12. Lee $\mathbf{J}$ (2020) Mental health effects of school closures during COVID-19. The Lancet Child Adolescent Health 4(6):421. https://doi.org/10.1016/S2352-4642(20)30109-7

13. Poletti M, Raballo A (2020) Letter to the editor: Evidence on school closure and children's social contact: useful for coronavirus disease (COVID-19)? Euro Surveill. https://doi.org/10. 2807/1560-7917.ES.2020.25.17.2000758

14. Wang C, Pan R, Wan X, Tan Y, Xu L, McIntyre RS, Choo FN, Tran B, Ho R, Sharma VK, Ho C (2020) A longitudinal study on the mental health of general population during the COVID19 epidemic in China. Brain Behav Immun. https://doi.org/10. 1016/j.bbi.2020.04.028

15. Tian F, Li H, Tian S, Yang J, Shao J, Tian C (2020) Psychological symptoms of ordinary Chinese citizens based on SCL-90 during the level I emergency response to COVID-19. Psychiatry Res. https://doi.org/10.1016/j.psychres.2020.112992

16. Lee NUEVA, Meejung Chin J, Sung M (2020) How has COVID19 changed family life and well-being in Korea? J Comparat Family Studies 51:301-313. https://doi.org/10.3138/jcfs.51.3-4. 006

17. Pietromonaco PR, Overall NC (2020) Applying relationship science to evaluate how the COVID-19 pandemic may impact couples' relationships. Am Psychol. https://doi.org/10.1037/amp00 00714

18. Coyne LW, Gould ER, Grimaldi M, Wilson KG, Baffuto G, Biglan A (2020) First things first: parent psychological flexibility and self-compassion during COVID-19. Behav Analysis in Practice. https://doi.org/10.1007/s40617-020-00435-w

19. James Riegler NUEVA, Raj SP, Moscato SP, Narad EL, Kincaid ME (2020) Pilot trial of a telepsychotherapy parenting skills intervention for veteran families: Implications for managing parenting stress during COVID-19. J Psychother Integr 30(2):290-303. https://doi.org/10.1037/int0000220

20. PeltzDaks NUEVAJS, Rogge RD (2020) Mediators of the association between COVID-19-related stressors and parents' psychological flexibility and inflexibility: The roles of perceived sleep quality and energy. J Contextual Behav Sci 17:168-176. https://doi.org/ 10.1016/j.jcbs.2020.07.001]

21. Humphreys KL, Myint MT, Zeanah CH (2020) Increased risk for family violence during the COVID-19 pandemic. Pediatrics. https://doi.org/10.1542/peds.2020-0982

22. Pfefferbaum B, North CS (2020) Mental Health and the Covid-19 Pandemic. Advance online publication, The New England journal of medicine. https://doi.org/10.1056/NEJMp2008017

23. Orrù G, Ciacchini R, Gemignani A, Conversano C (2020) Psychological intervention measures during the COVID-19 pandemic. Clin Neuropsychiatry 17(2):76-79. https://doi.org/10.36131/ CN20200208

24. Goodman R (1997) The strengths and difficulties questionnaire: a research note. J Child Psychol Psychiatry 38:581-586

25. Buss A, Plomin R (1984) Temperament: Early Developing Personality Traits. Lawrence Erlbaum, Hillsdale, NJ

26. de la Osa N, Granero R, Penelo E et al (2014) Psychometric properties of the alabama parenting questionnaire-preschool revision (APQ-Pr) in 3 year-old Spanish preschoolers. J Child Family Studies 23:776-784. https://doi.org/10.1007/s10826-013-9730-5

27. IBM Corp. IBM SPSS Statistics for Windows [Internet]. Armonk, NY: IBM Corp; 2017. Available from: https://hadoop.apache.org

28. Powell, B., Cooper, G., Hoffman, K., Marvin, B. (2016). The Circle of Security Intervention: Enhancing Attachment in Early Parent-Child Relationships. Guilford Press

29. Sanders MR (2008) Triple P-Positive parenting program as a public health approach to strengthening parenting. J Fam Psychol 22(4):506-517. https://doi.org/10.1037/0893-3200.22.3.506

30. Webster-Stratton C (2016) The Incredible Years parent programs: Methods and principles that support program fidelity. In: Ponzetti 
JJ (ed) Evidence-based parenting education: A global perspective. Routledge, New York, pp 143-160

31. Casey P, Cowan PA, Cowan CP, Draper L, Mwamba N, Hewison D (2017) Parents as partners: A UK Trial of a US couples-based parenting intervention for at-risk low-income families. Fam Process 56(3):589-606. https://doi.org/10.1111/famp.12289

32. Lucksted A, McFarlane W, Downing D, Dixon L, Adams C (2012) Recent developments in family psychoeducation as an evidencebased practice. J Marital Fam Ther 38(1):101-121

33. Sexton TL, Kinser JC, Hanes CW (2008) Beyond a single standard Levels of evidence approach for evaluating marriage and family therapy research and practice. J Family Therapy 30(4):386-398

34. Szabo TG, Richling S, Embry DD, Biglan A, Wilson KG (2020) From helpless to hero: promoting values-based behavior and positive family interaction in the midst of COVID-19. Behav Anal Pract. https://doi.org/10.1007/s40617-020-00431-0

35. Bobes MT, Jover M, Llácer B, Carot JM, Sanjuan J (2011) Adaptación española del EAS temperament survey para la evaluación del temperamento infantil. Pscothema 23(1):160-166

36. Ezpeleta L, Granero R, de la Osa N, Penelo E, Domènech JM (2013) Psychometric properties of the strengths and difficulties questionnaire $3-4$ in 3 year- old preschoolers. Compr Psychiatry 54(3):282-291. https://doi.org/10.1016/j.comppsych.2012.07.009

37. Ezpeleta L, de la Osa N, Doménech JM (2014) Prevalence of DSM-IV disorders, comorbidity and impairment in 3-yearold Spanish preschoolers. Soc Psychiatry Psychiatr Epidemiol 49(1):145-155. https://doi.org/10.1007/s00127-013-0683-1

38. Jiao WY, Wang LN, Liu J, Fang SF, Jiao FY, Pettoello-Mantovani M, Somekh E (2020) Behavioral and emotional disorders in children during the COVID-19 epidemic. J Pediatr 221:264-266.e1. https://doi.org/10.1016/j.jpeds.2020.03.013

39. Lorber MF, Egeland B (2011) Parenting and infant difficulty: testing a mutual exacerbation hypothesis to predict early onset conduct problems. Child Dev 82(6):2006-2020. https://doi.org/ 10.1111/j.1467-8624.2011.01652.x

40. Cicchetti D, Rogosch FA (2009) Adaptive coping under conditions of extreme stress: multilevel influences on the determinants of resilience in maltreated children. New Dir Child Adolesc Dev 2009(124):47-59. https://doi.org/10.1002/cd.242

41. Miller TW (1995) Stress adaptation in children: theoretical models. J Contemporary Psychotherapy 25(1):5-14. https://doi.org/ 10.1007/BF02308665]

42. Sentse M, Kretschmer T, de Haan A, Prinzie P (2017) Conduct problem trajectories between Age 4 and 17 and their association with behavioral adjustment in emerging adulthood. J Youth Adolesc 46(8):1633-1642. https://doi.org/10.1007/s10964-016-0476-4

43. Hill AL, Degnan KA, Calkins SD, Keane SP (2006) Profiles of externalizing behavior problems for boys and girls across preschool: The roles of emotion regulation and inattention. Dev Psychol 42(5):913-928. https://doi.org/10.1037/0012-1649.42.5.913

44. Bongers IL, Koot HM, van der Ende J, Verhulst FC (2003) The normative development of child and adolescent problem behavior. J Abnorm Psychol 112(2):179-192. https://doi.org/10.1037/0021843X.112.2.179
45. Bould H, Joinson C, Sterne J, Araya R (2013) The Emotionality Activity sociability temperament survey: factor analysis and temporal stability in a longitudinal cohort. Personality Individ Differ 54(5):628-633. https://doi.org/10.1016/j.paid.2012.11.010

46. METRA (2003). Menores con trastornos psíquicos y contexto familiar. Un estudio en la Comunidad de Madrid. Madrid: Fundación Ramón Areces y Universidad Pontificia Comillas.

47. Mesman J, Bongers IL, Koot HM (2001) Preschool developmental pathways to preadolescent internalizing and externalizing problems. J Child Psychol Psychiatry 42(5):679-689

48. McHale SM, Crouter AC, McGuire SA (1995) Congruence between mothers' and fathers; differential treatment of siblings: links with family relations and children's well-being. Child Dev 66(1):116-128

49. McHale SM, Updegraff KA, Jackson Newsom J, Tucker CJ (2000) When does parents' differential treatment have negative implications for siblings? Social-Development 9(2):149-172

50. Newton EK, Thompson RA, Goodman M (2016) Individual differences in toddlers' prosociality: experiences in early relationships explain variability in prosocial behavior. Child Dev 87(6):17151726. https://doi.org/10.1111/cdev.12631

51. Woodward KE, Boeldt DL, Corley RP, DiLalla L, Friedman NP, Hewitt JK, Mullineaux PY, Robinson J, Rhee SH (2018) Correlates of positive parenting behaviors. Behav Genet 48:283-297. https://doi.org/10.1007/s10519-018-9906-2

52. McKee L, Roland E, Coffelt N, Olson AL, Forehand R, Massari C, Jones D, Gaffney CA, Zens MS (2007) Harsh discipline and child problem behaviors: the roles of positive parenting and gender. J Family Violence 22:187-196. https://doi.org/10.1007/ s10896-007-9070-6

53. Edwards RC, Hans SL (2015) Infant risk factors associated with internalizing, externalizing, and co-occurring behavior problems in young children. Dev Psychol 51(4):489. https://doi.org/10. 1037/a0038800

54. Usher K, Bhullar N, Durkin J, Gyamfi N, Jackson D (2020) Family violence and COVID-19: increased vulnerability and reduced options for support. Int J Ment Health Nurs. https://doi.org/10. 1111/inm. 12735

55. Inchausti F, MacBeth A, Hasson-Ohayon I, Dimaggio G (2020) Psychological intervention and COVID-19: What we know so far and what we can do. J Contemp Psychotherapy. https://doi.org/ 10.1007/s10879-020-09460-w

56. Duan L, Zhu G (2020) Psychological interventions for people affected by the COVID-19 epidemic. The lancet psychiatry 7(4):300-302. https://doi.org/10.1016/S2215-0366(20)30073-0

Publisher's Note Springer Nature remains neutral with regard to jurisdictional claims in published maps and institutional affiliations. 